\title{
Retrieval of Water Vapour Profiles from GLORIA Nadir Observations
}

\author{
Nils König ${ }^{1}$, Gerald Wetzel ${ }^{1}{ }^{\mathbb{C}}$, Michael Höpfner ${ }^{1, *}{ }^{\mathbb{C}}$, Felix Friedl-Vallon ${ }^{1} \mathbb{C}$, Sören Johansson ${ }^{1} \mathbb{C}^{\mathbb{D}}$,

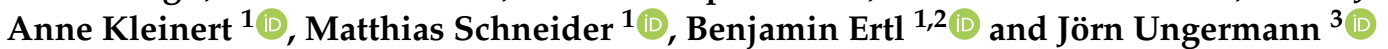

1 Institute of Meteorology and Climate Research, Karlsruhe Institute of Technology, Postfach 3640, 76021 Karlsruhe, Germany; nils.koenig.ka@gmail.com (N.K.); gerald.wetzel@kit.edu (G.W.); felix.friedl-vallon@kit.edu (F.F.-V.); soeren.johansson@kit.edu (S.J.); anne.kleinert@kit.edu (A.K.); matthias.schneider@kit.edu (M.S.); benjamin.ertl@kit.edu (B.E.)

2 Steinbuch Centre for Computing, Karlsruhe Institute of Technology, 76021 Karlsruhe, Germany

3 Institute of Energy and Climate Research, Stratosphere, Forschungszentrum Jülich, 52425 Jülich, Germany; j.ungermann@fz-juelich.de

* Correspondence: michael.hoepfner@kit.edu

check for updates

Citation: König, N.; Wetzel, G.; Höpfner, M.; Friedl-Vallon, F.; Johansson, S.; Kleinert, A.; Schneider, M.; Ertl, B.; Ungermann, J. Retrieval of Water Vapour Profiles from GLORIA Nadir Observations. Remote Sens. 2021, 13, 3675. https:// doi.org/10.3390/rs13183675

Academic Editors: Filomena Romano and Elisabetta Ricciardelli

Received: 28 July 2021

Accepted: 7 September 2021

Published: 14 September 2021

Publisher's Note: MDPI stays neutral with regard to jurisdictional claims in published maps and institutional affiliations.

Copyright: (c) 2021 by the authors. Licensee MDPI, Basel, Switzerland. This article is an open access article distributed under the terms and conditions of the Creative Commons Attribution (CC BY) license (https:/ / creativecommons.org/licenses/by/ $4.0 /)$.

\begin{abstract}
We present the first analysis of water vapour profiles derived from nadir measurements by the infrared imaging Fourier transform spectrometer GLORIA (Gimballed Limb Observer for Radiance Imaging of the Atmosphere). The measurements were performed on 27 September 2017, during the WISE (Wave driven ISentropic Exchange) campaign aboard the HALO aircraft over the North Atlantic in an area between $37^{\circ}-50^{\circ} \mathrm{N}$ and $20^{\circ}-28^{\circ} \mathrm{W}$. From each nadir recording of the 2-D imaging spectrometer, the spectral radiances of all non-cloudy pixels have been averaged after application of a newly developed cloud filter. From these mid-infrared nadir spectra, vertical profiles of $\mathrm{H}_{2} \mathrm{O}$ have been retrieved with a vertical resolution corresponding to five degrees of freedom below the aircraft. Uncertainties in radiometric calibration, temperature and spectroscopy have been identified as dominating error sources. Comparing retrievals resulting from two different a priori assumptions (constant exponential vs. ERA 5 reanalysis data) revealed parts of the flight where the observations clearly show inconsistencies with the ERA 5 water vapour fields. Further, a water vapour inversion at around $6 \mathrm{~km}$ altitude could be identified in the nadir retrievals and confirmed by a nearby radiosonde ascent. An intercomparison of multiple water vapour profiles from GLORIA in nadir and limb observational modes, IASI (Infrared Atmospheric Sounding Interferometer) satellite data from two different retrieval processors, and radiosonde measurements shows a broad consistency between the profiles. The comparison shows how fine vertical structures are represented by nadir sounders as well as the influence of a priori information on the retrievals.
\end{abstract}

Keywords: atmospheric remote sensing; water vapour; nadir viewing; limb viewing; infrared; Fourier-transform infrared spectroscopy

\section{Introduction}

Satellite instruments observing the upwelling thermal emission of the Earth's surface and atmosphere with high spectral resolution are established as important tools for weather forecast, air quality, and atmospheric research. Well-known space-borne nadir sounders are the Tropospheric Emission Spectrometer (TES) on NASA's Aura spacecraft [1,2], the Atmospheric Infrared Sounder (AIRS) on NASA's Aqua satellite [3-5], the Cross-track Infrared Sounders (CrIS) flying on the NOAA's Suomi NPP and NOAA-20 satellites [6] as well as the fleet of Infrared Atmospheric Sounding Interferometer (IASI) instruments on board EUMETSAT's Metop-A, -B, and -C satellites [7-10].

Operated from aircraft, besides dedicated scientific research, nadir instruments serve as predecessors of their space-borne counterparts as well as for quality assessments during validation campaigns. One of the first airborne nadir instruments working in the 
mid-infrared spectral region was the High-resolution Interferometer Sounder (HIS) [11]. Another airborne instrument is NAST-I (NPOESS Airborne Sounder Testbed Interferometer), which showed its capability to measure atmospheric profiles of water vapour, ozone, carbon monoxide, and the surface temperature [12]. Measurements of ARIES [13] (Airborne Research Interferometer Evaluation System); helped to characterize the properties of clouds [14] and to validate IASI with the observations of water vapour and temperature profiles $[15,16]$. A state-of-the-art airborne mid-infrared imaging Fourier transform spectrometer is the Gimballed Limb Observer for Radiance Imaging of the Atmosphere (GLORIA) instrument $[17,18]$. Up to now, GLORIA has mostly been used for measurements in the limb configuration aboard the high-flying aircraft Geophysica $[19,20]$ and during several campaigns of the German research aircraft HALO [21-23]. Depending on cloud top height, GLORIA can measure in limb mode down to 5-6 km. To sound also the atmosphere below, GLORIA is capable to switch its line of sight to nadir mode on the HALO aircraft, making it the first airborne instrument with limb as well as nadir observational capabilities.

In this work we present an initial characterization of the capabilities of GLORIA's nadir observations on basis of water vapour retrievals from measurements taken over the Atlantic Ocean in autumn 2017. In Section 2 we present details about the GLORIA instrument, the cloud filter algorithm and information about the retrieval process as well as the characterization of the retrieval results including a detailed error estimation. Section 3 is concerned with the nadir measurements during one flight of HALO. The derived crosssections of water vapour along the flight track are discussed along with comparisons to GLORIA limb observations as well as nearby IASI measurements and meteorological model analyses.

\section{Materials and Methods}

\subsection{GLORIA Instrument}

The GLORIA instrument is an imaging Fourier transform spectrometer which analyses the infrared radiation between 750 and $1400 \mathrm{~cm}^{-1}$. It has a 2-D detector array that simultaneously records $48 \times 128$ interferograms per measurement. To reduce the spectral noise, the spectrometer is cooled down to a temperature around $220 \mathrm{~K}$ [24]. In nadir mode, at an altitude of $12 \mathrm{~km}$ the detector's total field of view spans approximately $1664 \mathrm{~m} \times 624 \mathrm{~m}$ at ground level. The maximum optical path difference (OPD) of the interferometer can be set between $8 \mathrm{~cm}$ and $0.8 \mathrm{~cm}$ which corresponds to a spectral sampling (defined here as $1 /(2 \mathrm{OPD}))$ of $0.0625 \mathrm{~cm}^{-1}$ and $0.625 \mathrm{~cm}^{-1}$, respectively. The temporal resolution is $13 \mathrm{~s}$ for the fine and $2 \mathrm{~s}$ for the coarse spectral sampling. Considering the HALO aircraft speed over ground, the instrument covers a distance of approximately $3.1 \mathrm{~km}$ in high spectral resolution mode $(8 \mathrm{~cm}$ OPD) at an altitude of $12 \mathrm{~km}$. The gimbal mount of the instrument provides agility on all three axes which is especially important in case of limb imaging observations where the detector rows have to be aligned horizontally. During a measurement in nadir mode, the mount enables the detector to stare at a fixed position on the surface or to lock the detector parallel to the surface. During the flight analysed here, the second mode was set since no localized targets of water vapour are expected over the ocean.

Figure 1 shows the limb and nadir port in the belly pod of the HALO aircraft. For a more detailed description of the instrument, the characterization of calibrated spectra and more information on GLORIA's limb capabilities, the reader is referred to $[17,18,25,26]$. 


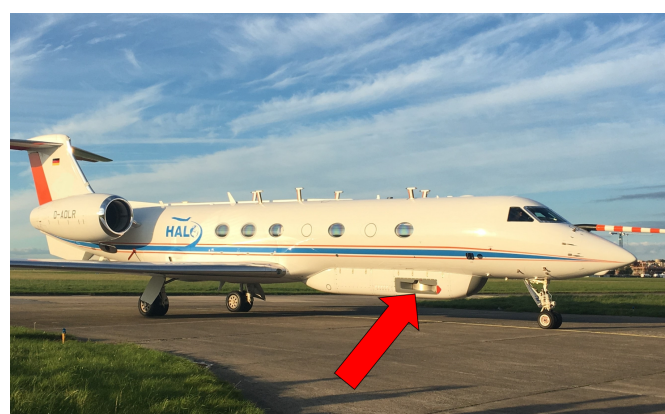

(a) Limb port

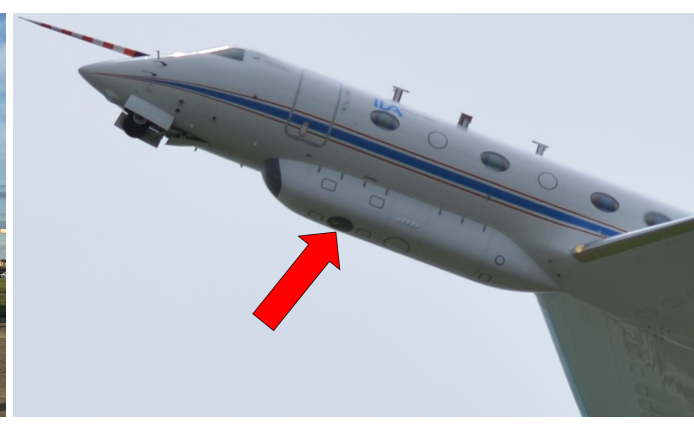

(b) Nadir port

Figure 1. Visual representation of (a) the limb and (b) nadir port in the belly pod below the HALO aircraft. The ports are indicated by the red arrows.

\subsection{Determination of Mean Spectra and Cloud Filtering}

For this first analysis of GLORIA nadir observations, we decided to average all cloudfree spectra of the GLORIA detector array pixels from one interferometer scan to analyse the best possible case regarding the signal to noise ratio. This approach is justified since all nadir measurements that are analysed in the following were taken over water where no significant small-scale variations of the water vapour profile within the detector's field of view are expected.

To reduce the cloud influence on these averaged spectra, two different filter approaches have been applied and their threshold values were optimized for this specific flight. The first approach analyses interferograms to identify small clouds. The second approach takes the spectrally averaged radiance of the spectra and compares it to the expected radiance in cloud-free conditions. This is similar to a cloud detection scheme used by Allen et al. (2014) [16]. Their approach is based on the difference in the brightness temperature between an atmospheric window and a non-window spectral region.

The first approach uses the raw interferogram to detect clouds that cross the pixel's field of view during the interferogram recording process. This is especially important for aircraft-based measurements where the cloud scene during interferogram recording may change rapidly due to the fast aircraft movement. In Figure 2, two interferograms with different levels of cloud influence are shown. Figure 2a depicts an interferogram with weak influence and Figure $2 \mathrm{~b}$ an interferogram which is more strongly influenced by clouds. By using the median of the interferogram, a decision is made whether the measurement of a pixel is cloud-free. If more than 10 percent of the interferogram values deviate from the median by a certain threshold, the spectrum of the pixel is not used for the averaging. This threshold was determined empirically to ensure that the influence of the clouds is not too strong, but that sufficient measurements are still available for a valid mean spectrum.

The second filter approach uses the spectrally averaged radiance of each individual detector pixel to decide whether there is a compact cloud in the pixel's field of view or not. This filter is based on the fact that the upwelling infrared radiation from cloud tops is generally lower than the spectral radiation from the surface. As a result, the spectrum of the pixel shows lower values above a cloud. With the help of Planck's law and the ERA 5 surface temperature, a reference value is calculated. If the radiation of the measurement deviates more than 10 percent from the reference value, the spectrum of the pixel is not used for the averaging.

After the application of the two filters and for further reduction of the cloud influence on the measurement and to filter out possible cloud edges, the directly neighbouring pixels in each direction of cloud flagged pixels are also discarded. An example for the effect of the filtering algorithm is presented in Figure 3. The continuous white lines between other lines occur due to problems with the readout electronics during this specific flight. However, beside slightly worsening the possible noise-reduction by averaging all pixels, this has no influence on the quality of the measurements. 

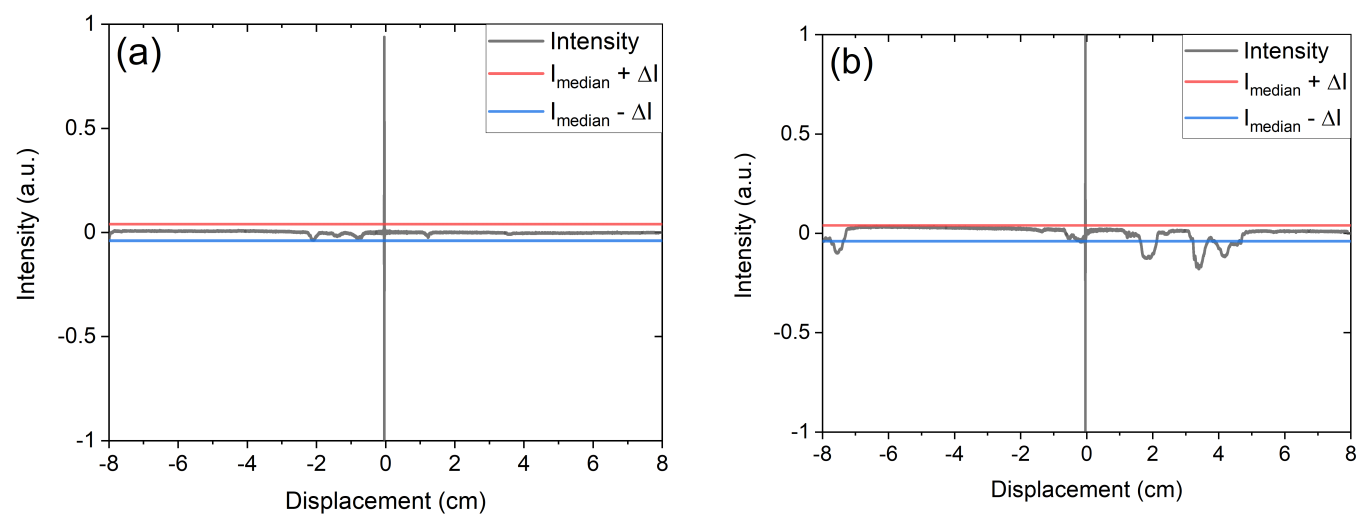

Figure 2. Visual representation of the interferogram based cloud filter. (a) shows an interferogram with a weak cloud influence and (b) an interferogram with a strong influence. Both interferograms are from different detector pixels for the same measurement. If more than 10 percent of the intensity values are off the defined boundaries, the measurement of the detector pixel is not taken into account when averaging.

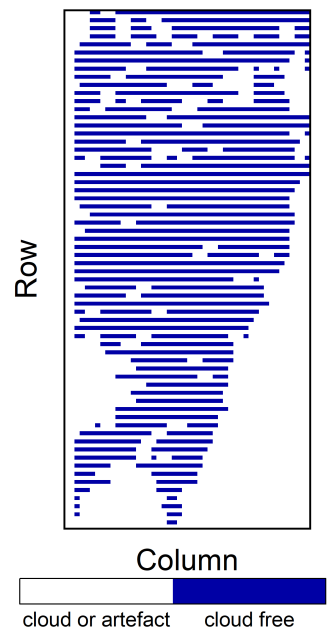

Figure 3. Exemplary representation of the pixels of the detector field after filtering. The continuous white lines in the rows are measurement artefacts due to problems with the readout electronics during the flight.

\subsection{Retrieval Process}

Retrieval of atmospheric profiles from the nadir spectra was performed with the algorithm KOPRAFIT [27]. It is based on the radiative transfer model KOPRA [28] (Karlsruhe Optimized and Precise Radiative transfer Algorithm). The applied retrieval approach is a constrained non-linear multi-parameter fit of the simulated nadir-radiance to the observed spectra. Atmospheric profiles are represented by the vector of unknowns, $\vec{x}$, which is determined in a Newtonian iteration process to account for the non-linearity of the atmospheric radiative transfer [29]:

$$
\vec{x}_{i+1}=\vec{x}_{i}+\left(\mathbf{K}_{\mathbf{i}}^{T} \mathbf{S}_{y}^{-1} \mathbf{K}_{\mathbf{i}}+\mathbf{R}\right)^{-1}\left(\mathbf{K}_{\mathbf{i}}^{T} \mathbf{S}_{y}^{-1}\left(\vec{y}_{\text {meas }}-F\left(\vec{x}_{i}\right)\right)-\mathbf{R}\left(\vec{x}_{i}-\vec{x}_{a}\right)\right) .
$$

$\vec{y}_{\text {meas }}$ contains the measured spectral radiances of the nadir view, and $\mathbf{S}_{y}$ is the related measurement noise covariance matrix. $F\left(\vec{x}_{i}\right)$ denotes the spectra calculated by the radiative transfer model using the first guess atmospheric state parameters $\vec{x}_{i}$ of iteration number $i$. $\mathbf{K}_{\mathbf{i}}$ is the Jacobian matrix, i.e., the partial derivatives $\partial F\left(\vec{x}_{i}\right) / \partial \vec{x}_{i}$. $\mathbf{R}$ denotes a regularization matrix and $\vec{x}_{a}$ the a priori information. 
The retrievals are performed at $250 \mathrm{~m}$ spaced vertical grid levels. This implies undersampling by the measurements and, thus, a vertical constraint is needed to avoid retrieval instabilities. For the regularization a first-order smoothing constraint $\mathbf{R}=\gamma \mathbf{L}^{\mathbf{T}} \mathbf{L}$ with the altitude-independent regularization parameter $\gamma$ is used. $\mathbf{L}$ is a first order finite differences operator [30]. To determine the vertical resolution of the retrieved altitude profiles, the averaging kernel is analysed:

$$
\mathbf{A}=\left(\mathbf{K}^{T} \mathbf{S}_{y}^{-1} \mathbf{K}+\mathbf{R}\right)^{-1} \mathbf{K}^{T} \mathbf{S}_{y}^{-1} \mathbf{K}
$$

From A, the vertical resolution can be determined in terms of the full width at half maximum of the related row of the averaging kernel matrix. Another approach to determine the vertical resolution is to divide the grid level distance by the diagonal values of $\mathbf{A}$ [29]. $\mathbf{K}$ is the Jacobian matrix of the last iteration.

For the retrieval, all nadir measurements of the flight with a maximum optical path difference of $1.4 \mathrm{~cm}\left(0.36 \mathrm{~cm}^{-1}\right.$ spectral sampling $)$ are analysed. In addition to $\mathrm{H}_{2} \mathrm{O}$, its isotopomer $\mathrm{HDO}$, and the trace gases $\mathrm{N}_{2} \mathrm{O}, \mathrm{CH}_{4}$ as well as the surface temperature are adjusted independently in the retrieval. It should be mentioned that in the absence of suitable $\mathrm{CO}_{2}$ lines in the spectral range used, the atmospheric temperature was not fitted but was taken from the ECMWF ERA 5 data set. All gases are fitted as altitude profiles of the natural logarithm of the trace-gas volume mixing ratios $(\log (\mathrm{VMR}))$. The information about the initial guess for surface temperature and the temperature profile originate from the ERA 5 database [31] and are interpolated to the GLORIA nadir point locations. For $\mathrm{N}_{2} \mathrm{O}$ and $\mathrm{CH}_{4}$ climatological profiles for the mid latitudes are used as initial guess and a priori profiles. For $\mathrm{H}_{2} \mathrm{O}$ two tests are performed: one using the ERA5 profiles as a priori and initial guess and the second by using an exponential decrease of $\mathrm{H}_{2} \mathrm{O}$ mixing ratios with altitude. The HDO a priori profiles are derived from the $\mathrm{H}_{2} \mathrm{O}$ a priori data by scaling with the Standard Mean Ocean Water (SMOW) ratio. In addition to the retrieved gases, $\mathrm{CO}_{2}$ is included in the forward calculation as climatological profile taking into account the current $\mathrm{CO}_{2}$ value (403 ppmv) during the campaign. For the regularization of the retrieval a distinct number of degrees of freedom (DOF) is prescribed. Then the gammaparameter of the smoothing operator is adjusted during the iteration steps so that the prescribed DOF-number is reached. For $\mathrm{H}_{2} \mathrm{O}, 5$ degrees of freedom are fixed, while for the other gases 3 degrees of freedom are taken into account. We used the wavenumber range of $1190-1400 \mathrm{~cm}^{-1}$ which has been shown to be suitable for the retrieval of $\mathrm{H}_{2} \mathrm{O}$ from IASI spectra [32,33]. The surface emissivity of the ocean has been prescribed to 0.976 $\left(2564 \mathrm{~cm}^{-1}\right)$ and $0.993\left(869 \mathrm{~cm}^{-1}\right)$ according to [34] and has been interpolated linearly within the analysed spectral window.

\subsection{Retrieval Diagnostics}

The error estimation is illustrated here for a sample measurement during the aircraft campaign described below. It was recorded at $41.46^{\circ} \mathrm{N}$ and $27.9^{\circ} \mathrm{W}$ about $300 \mathrm{~km}$ north of the Azores from a flight level of $11.76 \mathrm{~km}$ at 10:30:40 UTC. The retrieval scheme directly propagates the spectral noise into the resulting profiles. Typical values for the spectral noise (noise equivalent spectral radiance, NESR) are derived from the imaginary part of the interferograms. For the actual case, a value of $5.9 \mathrm{nW}\left(\mathrm{cm}^{-1} \mathrm{sr} \mathrm{cm}^{2}\right)^{-1}$ for the averaged spectrum over the selected pixels has been applied.

To estimate the effect of parameter errors on the result, repeated retrieval calculations have been performed with varying parameters. The effect of radiometric calibration uncertainties has been modelled by an additive spectrally constant offset error of $30 \mathrm{nW}\left(\mathrm{cm}^{-1} \mathrm{sr} \mathrm{cm}^{2}\right)^{-1}$ and a multiplicative scaling error of $1 \%$ [35]. A temperature error of $1 \mathrm{~K}$ is applied to test its effect on the resulting water vapour profile. To estimate the influence of spectroscopic uncertainties, an error of $3-15 \%$ is assumed for the line intensity and an error of $20 \%$ for pressure broadening [36].

Figure $4 \mathrm{a}$ shows the match between the modelled spectrum of the last iteration and the observed one. In Figure $4 b$ (top), the residual of the two spectra can be seen as a red 
line together with the Root of Mean Squares (RMS) as a black line and the 3- $\sigma$ range of the RMS as a black dashed line.

The RMS value of $13.2 \mathrm{nW}\left(\mathrm{cm}^{-1} \mathrm{sr} \mathrm{cm}^{2}\right)^{-1}$ is about twice as large as the instrumental NESR. We mainly attribute this to spectroscopic uncertainties affecting the simulated radiances. For example, the largest residual peak at around $1253.9 \mathrm{~cm}^{-1}$ correlates to spectral transitions of $\mathrm{N}_{2} \mathrm{O}$ and $\mathrm{CH}_{4}$. A simulated nadir spectrum taking only into account $\mathrm{H}_{2} \mathrm{O}$ lines is shown in the bottom part of Figure $4 \mathrm{~b}$ and helps to identify $\mathrm{H}_{2} \mathrm{O}$ signatures in the measured spectrum displayed in Figure $4 \mathrm{~b}$ (top)

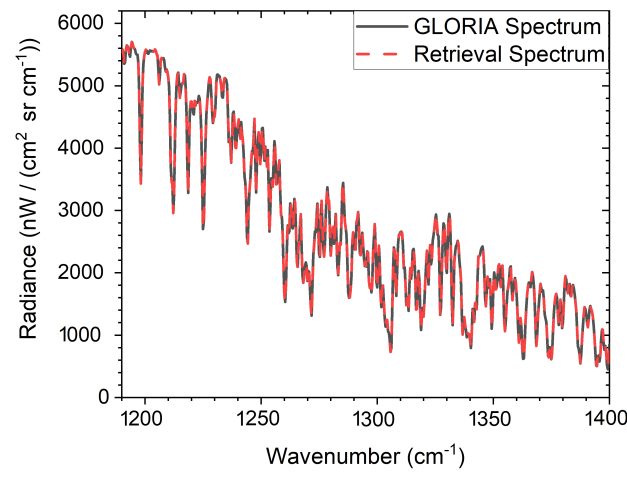

(a)

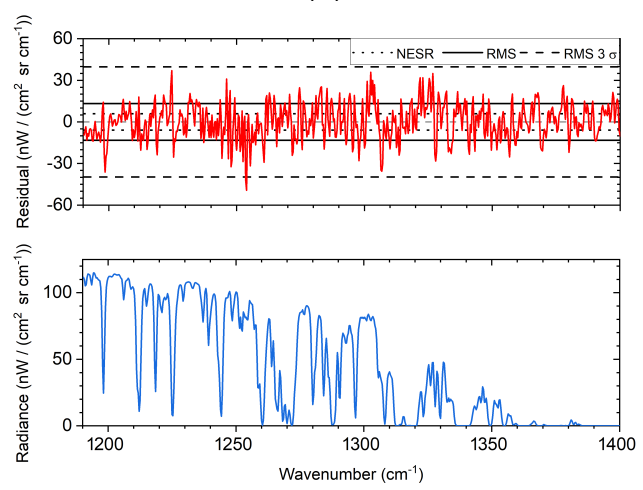

(b)

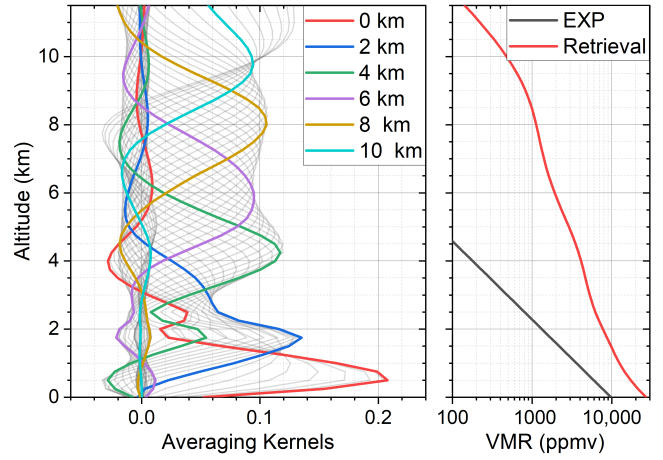

(c)

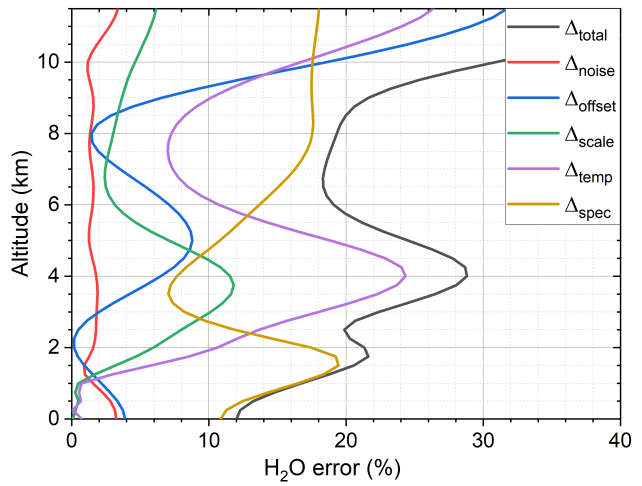

(d)

Figure 4. Retrieval characterization of the $\mathrm{H}_{2} \mathrm{O}$ profile for the GLORIA nadir measurement at 10:30:40 UTC. (a) measured (black) and fitted (red) spectra, (b) residual difference between measured and fitted spectrum (top) and the simulated signatures of $\mathrm{H}_{2} \mathrm{O}$ (bottom), (c) averaging kernel rows and the a priori and retrieved water vapour profile and (d) different error components and the total estimated error.

Figure $4 \mathrm{c}$ illustrates the rows of the averaging kernel matrix. Some kernels are highlighted with colours. With the exception of the averaging kernel for the ground-level, all coloured kernels reach their maximum near to the associated altitude. The peak of the ground-level kernel below $1 \mathrm{~km}$ indicates that the retrieval results of the ground-level layers mostly illustrate information from around $1 \mathrm{~km} \mathrm{[33]} \mathrm{and} \mathrm{only} \mathrm{to} \mathrm{a} \mathrm{small} \mathrm{extent}$ information from the ground. A lower sensitivity of the retrieval between 2 and $4 \mathrm{~km}$ altitude is indicated by the lack of pronounced peaks of the kernels there. This is caused by an inversion of the temperature profile in this altitude range. The increase in the temperature error and the scaling error also speak for the temperature as the trigger for the lower sensitivity.

In Figure $4 \mathrm{~d}$ different error components and the total estimated error are shown. The total estimated error is determined as the square root of the sum of the squares of the individual error components. In contrast to the averaging kernel, the total estimated 
error peaks at an altitude of $4 \mathrm{~km}$. Up to an altitude of $10 \mathrm{~km}$ the average of the estimated total error value is $21 \%$. The noise error is almost constant over the entire profile with an average value of $1.6 \%$. Near the ground and the top of the measurement the error increases to values of around 3.2\%. In contrast to the noise error, the other errors vary more strongly over the entire profile. The scaling error reaches a maximum deviation of around $11.8 \%$ at a height of $3.75 \mathrm{~km}$ and is around $4.9 \%$ below $10 \mathrm{~km}$. In the case of a temperature error, the maximum deviation is $24.3 \%$. Up to $10 \mathrm{~km}$ the temperature error is on average $11.6 \%$ and is more than twice as large as the scaling error. The offset error reaches a mean value of $5 \%$ below $10 \mathrm{~km}$. In this special case, the offset error has only a weak influence on the water vapour profile in the area around $2.25 \mathrm{~km}$. The spectroscopic error leads to an average error of $14 \%$ up to $10 \mathrm{~km}$ and dominates the total error below $2.5 \mathrm{~km}$ and between $6-9 \mathrm{~km}$. The spectroscopic error predominates in the layers in which the water vapour changes most with altitude. In the range from 2.5 to $5.75 \mathrm{~km}$ the temperature error predominates, which can be attributed to the present temperature inversion. An explanation for the increase in temperature and offset errors above $10 \mathrm{~km}$ are the low water vapour values, where even small differences in those parameters can lead to large relative uncertainties.

\subsection{IASI Measurements}

The Infrared Atmospheric Sounding Interferometer (IASI) is a remote sensing nadir instrument which operates on board the Metop satellites. Its goal is to record highly resolved temperature, water vapour and trace gas profiles. IASI measures in a spectral range between $645 \mathrm{~cm}^{-1}$ and $2760 \mathrm{~cm}^{-1}$ with a spectral sampling of 0.35 to $0.50 \mathrm{~cm}^{-1}$.

For comparison with GLORIA, we use observations from the Metop-A IASI instrument in the vicinity of our airborne nadir measurement locations. Results from EUMETSAT as well as data retrieved at Karlsruhe Institute of Technology (KIT) are shown. While the EUMETSAT retrieval uses the entire spectral range of IASI, the KIT retrieval uses a spectral window from 1190-1400 $\mathrm{cm}^{-1}[9,10,33]$.

\section{Results}

\subsection{Flight Data}

Based at Shannon Airport in Ireland $\left(52.70^{\circ} \mathrm{N}, 8.86^{\circ} \mathrm{W}\right)$, the Wave-driven Isentropic Exchange Campaign (WISE) took place in September and October 2017. During the flight on 27 September, GLORIA performed measurements in nadir mode (Figure 5). A total of 902 nadir measurements were recorded with different OPDs during different sections of the flight. For a consistent data analysis we analyse all of them with an OPD of $1.4 \mathrm{~cm}$. Nadir measurements were recorded in two regions during this flight (see black dots Figure 5). The northern region of the nadir measurements is around $50^{\circ} \mathrm{N}$ and between 20 and $26^{\circ} \mathrm{W}$. The southern region lies around $28^{\circ} \mathrm{W}$ and between 37 and $43^{\circ} \mathrm{N}$.

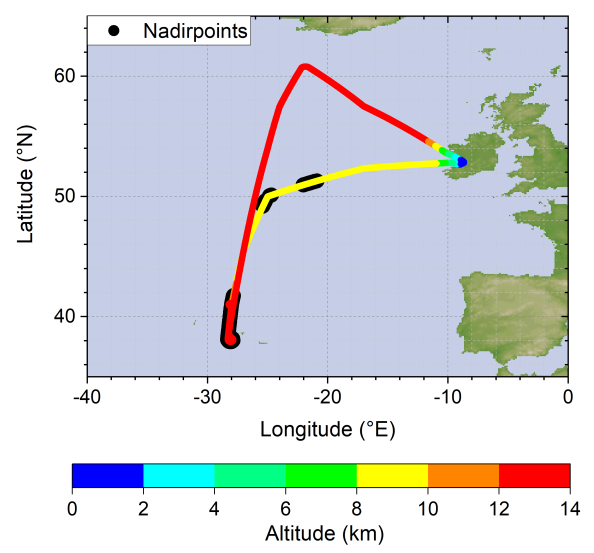

Figure 5. Flight track of WISE campaign flight F06 on 27 September 2017, colour coded for aircraft GPS altitude as indicated by the legend. Black dots indicate time slots where GLORIA was operated in the nadir viewing mode. 


\subsection{Cross Sections}

Figure 6 displays cross-sections of retrieved and ERA 5 water vapour profiles along the flight. From the initial 902 nadir measurements, 502 remained after cloud filtering and 439 converged. In Figure 6a the retrieved water vapour profiles are based on always the same exponential a priori profile (see Figure 4c). Even with this a priori choice, various structures show up in the retrieval results. For example, the water vapour inversion between $2 \mathrm{~km}$ and $4 \mathrm{~km}$ altitude at 10:45 UTC. More realistic a priori profiles are depicted in Figure $6 \mathrm{~b}$, which are the spatially and temporally interpolated ERA 5 data. These profiles serve as a a priori for the water vapour retrievals in the Figure $6 \mathrm{c}$.

Comparing the three panels in Figure 6 provides indications about the influence of the realistic ERA 5 a priori on the retrieval results as well as parts of the flight where information from the observations show clear differences from ERA 5. One example for the latter are the high volume mixing ratios between 2 and $4 \mathrm{~km}$ at around 10:45 UTC in Figure $6 \mathrm{a}, \mathrm{c}$, which are less pronounced in the ERA 5 data. A similar effect is visible around 8:45 UTC at $2 \mathrm{~km}$ altitude. On the other hand, the water vapour inversion above $2 \mathrm{~km}$ after 10:25 UTC in Figure 6c seems to be imprinted by use of the ERA 5 a priori profiles as well as the slight inversion around 8:45 UTC between 4 and $6 \mathrm{~km}$.

Other features that are different from the ERA 5 a priori are high retrieved water vapour volume mixing ratios near the ground. These are most evident in the measurements in the north. Further areas with higher VMR in contrast to the a priori values can be seen between 10:40 and 10:50 UTC at altitudes around $12 \mathrm{~km}$.

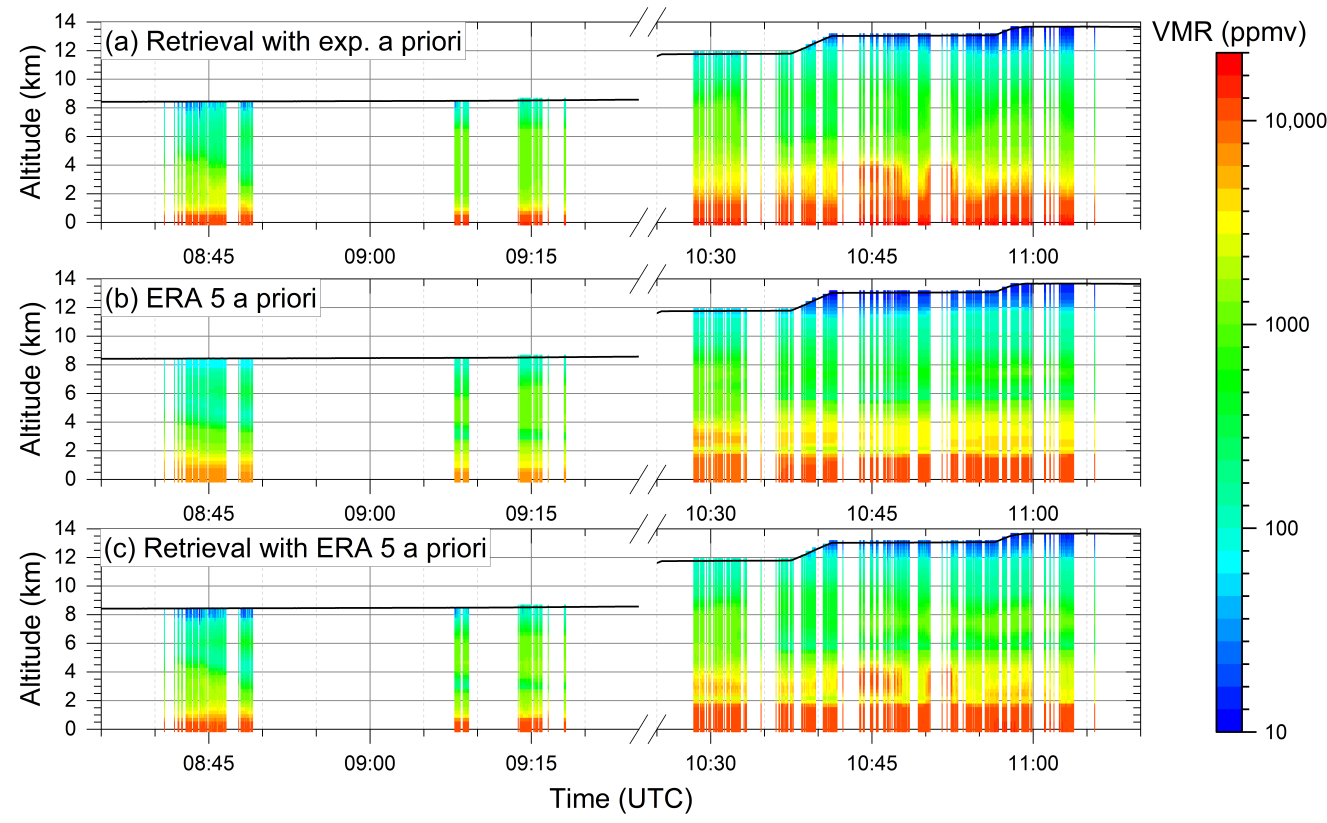

Figure 6. Cross sections of water vapour VMR profiles. (a) displays retrievals based on an exponential a priori profile. (b) shows the ERA 5 a priori profiles which are used for the retrievals in (c). The black lines indicate the observer altitude.

\subsection{Comparison of Mean Profiles}

Figure 7 displays two map projections indicating the position of GLORIA limb observations during flight as well as proximate IASI measurements. In addition to the flight trajectory, the tangent heights of the GLORIA limb measurements can be seen in Figure 7a. For better recognition the GLORIA nadir points are coloured green in this illustration. In Figure $7 \mathrm{~b}$, the nadir points of the IASI measurements are shown next to the flight path. The ovals in the map projections indicate the GLORIA and the IASI measurements, which are selected for a mean profile comparison. Co-located IASI observations have been se- 
lected such that the nadir points are located within one degree of longitude and latitude from the GLORIA nadir measurements.

A total of 316 GLORIA nadir measurements and ERA 5 a priori profiles, 259 GLORIA limb measurements and 63 IASI measurements were averaged for the mean profile comparison. Figure 8 presents a direct comparison of the mean profiles for the different instruments and the water vapour profile of the 11:30 UTC radiosonde ascent of the Graciosa station $\left(39.09^{\circ} \mathrm{N}, 28.03^{\circ} \mathrm{W}\right)$. Additionally, the $1-\sigma$ variability of the averaged profiles as error bars and the associated mean a priori profiles are presented in Figure 9. The radiosonde dataset clearly shows the large variability of water vapour with altitude indicating three major parts of deviation from a 'smooth' vertical profile at around $2 \mathrm{~km}$, between 5 and $7 \mathrm{~km}$ and between 8 and $10 \mathrm{~km}$. The second 'best' observations in terms of altitude resolution (around $0.5-0.7 \mathrm{~km}$ ) in this comparison are the GLORIA limb observations. These match well the dip in $\mathrm{H}_{2} \mathrm{O}$ mixing ratios between 6 and $8 \mathrm{~km}$ while the low values at $8-10 \mathrm{~km}$ are not visible in the mean. However, the variability (Figure 9) indicates, that the radiosonde values are mostly within the specified range.

The ERA5 reanalysis dataset clearly shows the two lower 'dips' at 2 and 5-7 km altitude while the negative deviation at $8-10 \mathrm{~km}$ is only slightly indicated (Figure 9). It is obvious that the GLORIA nadir retrieval results with ERA5 a priori even with five degrees of freedom are strongly pulled in the direction of the a priori by the Tikhonov smoothing operator. The GLORIA nadir observations with smooth exponential a priori profile show a tendency to lower values between 5 and $7 \mathrm{~km}$ as well as an indication of a dip at $2 \mathrm{~km}$. At $8-10 \mathrm{~km}$, however, there is no sign of a dent in the profile. Above approximately $8 \mathrm{~km}$ altitude both GLORIA nadir retrievals show a positive deviation compared to all other profiles hinting to an unknown systematic impact (Figure 8). This is also supported by the low variability of these two profiles at this altitude (Figure 9).

Compared to each other, both IASI retrieval results show similar behaviour. There is no clear sign of both dips at $5-7 \mathrm{~km}$ and $8-10 \mathrm{~km}$. While the KIT retrievals are clearly smaller between 5 and $7 \mathrm{~km}$ than their associated a priori profiles, the EUMETSAT retrievals are very similar to their a priori across the entire profile. The mean vertical resolution in the troposphere for the results of the KIT retrieval is 4.4 DOFs. This is slightly smaller than the 5.0 DOFs for the GLORIA nadir result and may be a reason for the less resolved profile. In the best case, the EUMETSAT retrieval can have up to 10 DOFs for the entire profile [37].

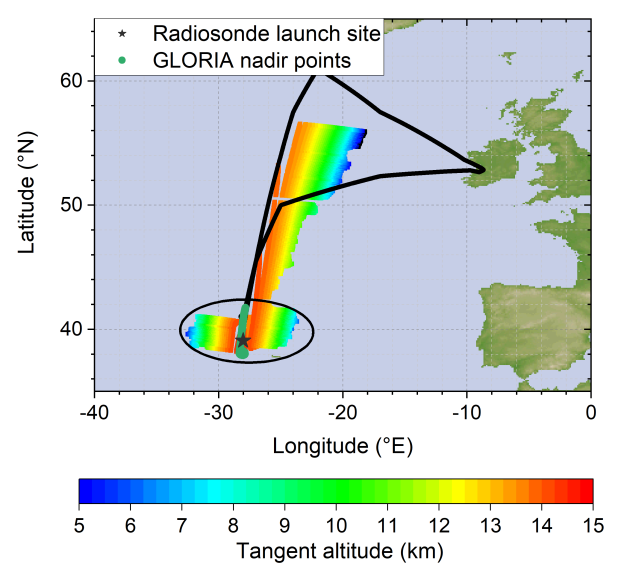

(a) GLORIA

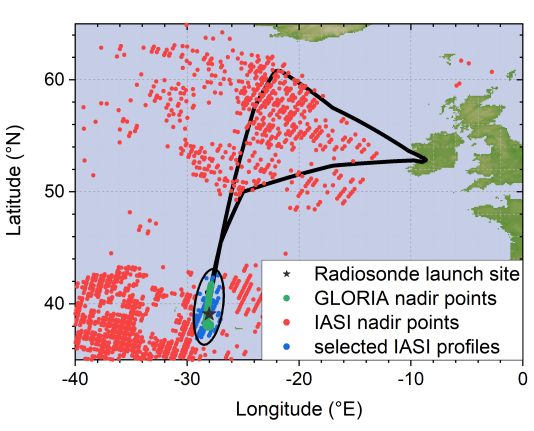

(b) IASI

Figure 7. Map projection of the GLORIA limb tangent altitudes and the IASI nadir points. The GLORIA limb tangent altitudes in (a) are colour coded. The red dots in (b) illustrate the IASI nadir positions, while the blue dots indicate the selected IASI profiles. The GLORIA nadir points are indicated by the green dots. The black ovals indicate the measurements that are used for the mean profile comparison and the grey star marks the position of the radiosonde launch site. 


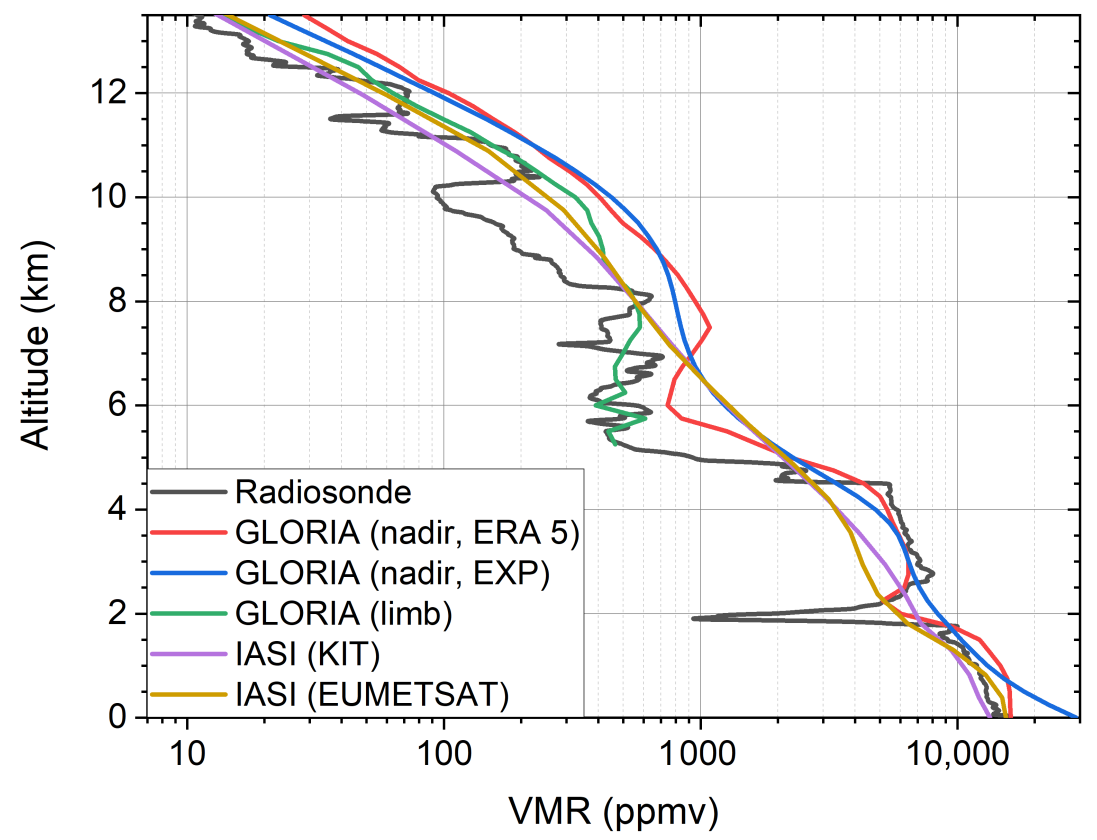

Figure 8. Various mean water vapour profiles in vicinity of the southern flight leg (see Figure 7a,b). The red and blue lines illustrate the mean profiles for the GLORIA nadir retrieval with the ERA 5 and the exponential a priori, respectively. The green line shows the mean profile for the GLORIA limb retrieval. The purple and ochre-coloured lines depict the IASI retrieval mean profiles from KIT and EUMETSAT, respectively. In addition, a radiosonde ascent of the Graciosa station on the Azores is shown in black.
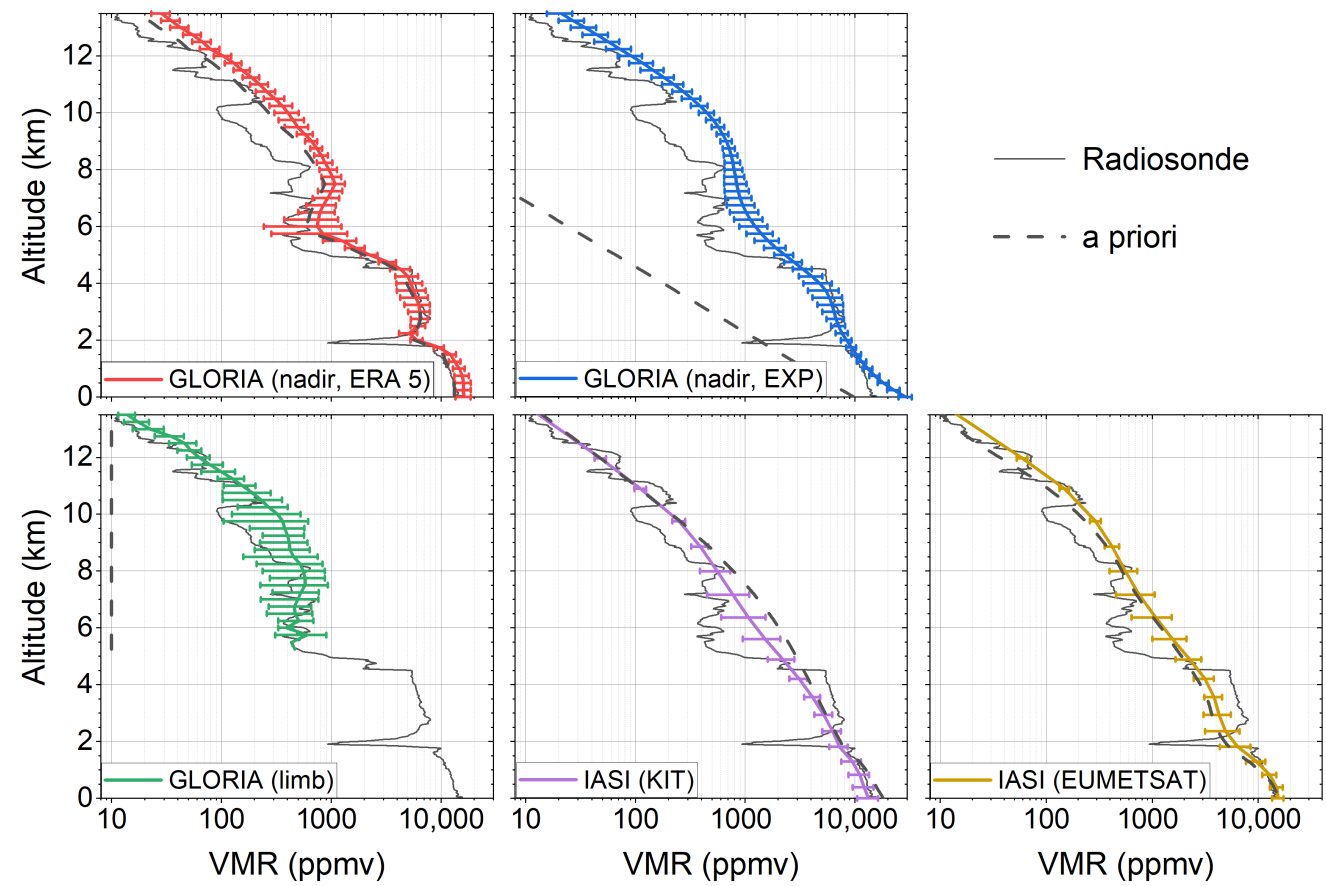

Figure 9. Same profiles as in Figure 8 with 1- $\sigma$ variability of the averaged profiles as error bars and the associated mean a priori profile as black dashed lines.

\section{Discussion}

In this study, we have examined for the first time the capability of the GLORIA instrument measuring water vapour profiles in the nadir mode on board of the research aircraft HALO during the WISE campaign. For the selection of spectra unaffected by 
clouds in the field-of-view during the time of recording an interferogram, we have applied a new approach to filter out the cloud influence based on both, the interferograms and the calibrated spectra.

Due to the application of averaged spectra from each nadir image, the estimated error caused by spectral noise is a minor contribution in the total error budget of the retrieved water vapour profiles. The most prominent contributions stem from uncertainties in the radiometric calibration, the assumed temperature profile as well as the spectroscopy. With a mean deviation of $11.6 \%$ and a peak of $24.3 \%$, the temperature error of GLORIA is in the same range as the corresponding IASI errors [32,33]. Overall, the mean estimated total error up to $10 \mathrm{~km}$ altitude is $21 \%$. Errors are largest between 2.5 and $5.5 \mathrm{~km}$ with a maximum peak of $28.8 \%$ at $4 \mathrm{~km}$. Above $9 \mathrm{~km}$ the total error increases again.

The mean profiles of the GLORIA nadir measurements show a good similarity with a radiosonde ascent of the station Graciosa on the Azores. They even indicate water vapour inversions at around $2 \mathrm{~km}$ and between 6 and $8 \mathrm{~km}$ altitude-though overestimating concentrations above about $8 \mathrm{~km}$. The mean GLORIA limb profile agrees very well with the values of the radiosonde and even represents the inversion above $6 \mathrm{~km}$. Overall the two mean IASI retrieval profiles are in line with the radiosonde water vapour values and the retrieved GLORIA profiles bearing in mind the coarse vertical resolution and the error uncertainties of the inferred data. However, only the IASI-EUMETSAT profile points at the water vapour inversion at $2 \mathrm{~km}$, while the inversion around $7 \mathrm{~km}$ is not visible.

This study has demonstrated the principal capability of GLORIA to measure $\mathrm{H}_{2} \mathrm{O}$ vertical profiles in the nadir observation mode with an overall accuracy of about $21 \%$ and five degrees of freedom in the troposphere corresponding to a vertical resolution of $2-4 \mathrm{~km}$. In further studies, it would be interesting to examine the influence of a better spectral resolution on the results since a previous study performed by [38] investigating nadir sounding with high spectral resolution has claimed total errors of retrieved $\mathrm{H}_{2} \mathrm{O}$ profiles around $10 \%$. Future work includes the analysis of GLORIA nadir measurements for other gases like $\mathrm{CH}_{4}, \mathrm{~N}_{2} \mathrm{O}$ and $\mathrm{O}_{3}$. In addition, as only sketched out in this study, a combined, more interlaced and locally overlapping recording of limb- and nadir spectra should help to better characterize the 3-D distribution of water vapour and other trace gases from near the ground up to flight level. Such an option could foster the quality assessment regarding the validation of satellite instruments.

Author Contributions: Conceptualization, N.K. and M.H.; methodology, N.K., G.W. and M.H.; software, N.K., S.J., M.H. and B.E.; investigation, N.K., M.H., F.F.-V., A.K., M.S. and J.U.; writingoriginal draft preparation, N.K.; writing—review and editing, G.W., M.H., F.F.-V., S.J., A.K., M.S. and J.U.; visualization, N.K.; supervision, M.H. and G.W. All authors have read and agreed to the published version of the manuscript.

Funding: Atmospheric research with HALO is supported by the Priority Programme SPP of the Deutsche Forschungsgemeinschaft (DFG) grant number 1294. The MUSICA IASI processing was funded by the Deutsche Forschungsgemeinschaft grant number 416767181 (project TEDDY).

Data Availability Statement: The GLORIA data used in this study are available on request from the authors. GLORIA limb viewing data can also be accessed at the HALO database (https: / doi. org/10.17616/R39Q0T (accessed on 13 September 2021), HALO consortium). IASI MUSICA data are available at the repository radar4KIT (https: / / doi.org/10.35097/412 (accessed on 13 September 2021), https: / / doi.org/10.35097 / 408 (accessed on 13 September 2021), Schneider, M., Ertl, B., and Diekmann, C.). ERA 5 data can be accessed at https://www.ecmwf.int/en/forecasts/datasets/reanalysisdatasets/era5 (accessed on 13 September 2021).

Acknowledgments: We acknowledge the WISE coordination team for excellently conducting the aircraft campaign. Results are based on the efforts of all members of the GLORIA team, including the technology institutes ZEA-1 and ZEA-2 at Forschungszentrum Jülich and the Institute for Data Processing and Electronics at the Karlsruhe Institute of Technology. The MUSICA IASI processing has been performed on the ForHLR and HoreKa supercomputers funded by the Ministry of Science, Research and the Arts Baden-Württemberg and by the German Federal Ministry of Education and 
Research. We thank ECMWF for providing the reanalysis data and EUMETSAT for IASI datasets. We acknowledge support by the KIT-Publication Fund of the Karlsruhe Institute of Technology.

Conflicts of Interest: The authors declare no conflict of interest.

\section{References}

1. Beer, R.; Glavich, T.A.; Rider, D.M. Tropospheric emission spectrometer for the Earth Observing System's Aura satellite. Appl. Opt. 2001, 40, 2356-2367. [CrossRef]

2. Worden, J.; Kulawik, S.; Frankenberg, C.; Payne, V.; Bowman, K.; Cady-Peirara, K.; Wecht, K.; Lee, J.E.; Noone, D. Profiles of CH $\mathrm{HDO}, \mathrm{H}_{2} \mathrm{O}$, and $\mathrm{N}_{2} \mathrm{O}$ with improved lower tropospheric vertical resolution from Aura TES radiances. Atmos. Meas. Tech. 2012, 5, 397-411. [CrossRef]

3. Aumann, H.H.; Pagano, R.J. Atmospheric infrared sounder on the Earth Observing System. Opt. Eng. 1994, 33, 776-784. [CrossRef]

4. Pagano, T.S.; Aumann, H.H.; Hagan, D.E.; Overoye, K. Prelaunch and in-flight radiometric calibration of the Atmospheric Infrared Sounder (AIRS). IEEE Trans. Geosci. Remote Sens. 2003, 41, 265-273. [CrossRef]

5. Divakarla, M.G.; Barnet, C.D.; Goldberg, M.D.; McMillin, L.M.; Maddy, E.; Wolf, W.; Zhou, L.; Liu, X. Validation of Atmospheric Infrared Sounder temperature and water vapor retrievals with matched radiosonde measurements and forecasts. J. Geophys. Res. Atmos. 2006, 111. [CrossRef]

6. Han, Y.; Revercomb, H.; Cromp, M.; Gu, D.; Johnson, D.; Mooney, D.; Scott, D.; Strow, L.; Bingham, G.; Borg, L.; et al. Suomi NPP CrIS measurements, sensor data record algorithm, calibration and validation activities, and record data quality. J. Geophys. Res. Atmos. 2013, 118, 12734-12748. [CrossRef]

7. Siméoni, D.; Singer, C.; Chalon, G. Infrared atmospheric sounding interferometer. Acta Astronaut. 1997, 40, 113-118. [CrossRef]

8. Pougatchev, N.; August, T.; Calbet, X.; Hultberg, T.; Oduleye, O.; Schlüssel, P.; Stiller, B.; St. Germain, K.; Bingham, G. IASI temperature and water vapor retrievals-Error assessment and validation. Atmos. Chem. Phys. 2009, 9, 6453-6458. [CrossRef]

9. August, T.; Klaes, D.; Schlüssel, P.; Hultberg, T.; Crapeau, M.; Arriaga, A.; O'Carroll, A.; Coppens, D.; Munro, R.; Calbet, X. IASI on Metop-A: Operational Level 2 retrievals after five years in orbit. J. Quant. Spectrosc. Radiat. Transf. 2012, 113, $1340-1371$. [CrossRef]

10. Schneider, M.; Ertl, B.; Diekmann, C.J.; Khosrawi, F.; Weber, A.; Hase, F.; Höpfner, M.; García, O.E.; Sepúlveda, E.; Kinnison, D. Design and description of the MUSICA IASI full retrieval product. Earth Syst. Sci. Data Discuss. 2021, 2021, 1-51. [CrossRef]

11. Revercomb, H.E.; LaPorte, D.D.; Smith, W.L.; Buijs, H.; Murcray, D.G.; Murcrayr, F.J.; Sromovsky, L.A. High-altitude aircraft measurements of upwelling IR radiance: Prelude to FTIR from geosynchronous satellite. Mikrochim. Acta 1988, 95, 439-444. [CrossRef]

12. Smith, W.L.; Zhou, D.K.; Larar, A.M.; Mango, S.A.; Howell, H.B.; Knuteson, R.O.; Revercomb, H.E. The NPOESS Airborne Sounding Testbed Interferometer-Remotely Sensed Surface and Atmospheric Conditions during CLAMS. J. Atmos. Sci. 2005, 62, 1118-1134. [CrossRef]

13. Wilson, S.H.S.; Atkinson, N.C.; Smith, J.A. The Development of an Airborne Infrared Interferometer for Meteorological Sounding Studies. J. Atmos. Ocean. Technol. 1999, 16, 1912-1927.<1912:Tdoaai>2.0.Co;2 [CrossRef]

14. Maestri, T.; Rizzi, R.; Smith, J.A. Spectral infrared analysis of a cirrus cloud based on Airborne Research Interferometer Evaluation System (ARIES) measurements. J. Geophys. Res. Atmos. 2005, 110. [CrossRef]

15. Illingworth, S.M.; Allen, G.; Newman, S.; Vance, A.; Marenco, F.; Harlow, R.C.; Taylor, J.; Moore, D.P.; Remedios, J.J. Atmospheric composition and thermodynamic retrievals from the ARIES airborne FTS system-Part 1: Technical aspects and simulated capability. Atmos. Meas. Tech. 2014, 7, 1133-1150. [CrossRef]

16. Allen, G.; Illingworth, S.M.; O'Shea, S.J.; Newman, S.; Vance, A.; Bauguitte, S.J.B.; Marenco, F.; Kent, J.; Bower, K.; Gallagher, M.W.; et al. Atmospheric composition and thermodynamic retrievals from the ARIES airborne TIR-FTS system-Part 2: Validation and results from aircraft campaigns. Atmos. Meas. Tech. 2014, 7, 4401-4416. [CrossRef]

17. Friedl-Vallon, F.; Gulde, T.; Hase, F.; Kleinert, A.; Kulessa, T.; Maucher, G.; Neubert, T.; Olschewski, F.; Piesch, C.; Preusse, P.; et al. Instrument concept of the imaging Fourier transform spectrometer GLORIA. Atmos. Meas. Tech. 2014, 7, 3565-3577. [CrossRef]

18. Riese, M.; Oelhaf, H.; Preusse, P.; Blank, J.; Ern, M.; Friedl-Vallon, F.; Fischer, H.; Guggenmoser, T.; Höpfner, M.; Hoor, P.; et al. Gimballed Limb Observer for Radiance Imaging of the Atmosphere (GLORIA) scientific objectives. Atmos. Meas. Tech. 2014, 7, 1915-1928. [CrossRef]

19. Höpfner, M.; Ungermann, J.; Borrmann, S.; Wagner, R.; Spang, R.; Riese, M.; Stiller, G.; Appel, O.; Batenburg, A.M.; Bucci, S.; et al. Ammonium nitrate particles formed in upper troposphere from ground ammonia sources during Asian monsoons. Nat. Geosci. 2019, 12, 608-612. [CrossRef]

20. Johansson, S.; Höpfner, M.; Kirner, O.; Wohltmann, I.; Bucci, S.; Legras, B.; Friedl-Vallon, F.; Glatthor, N.; Kretschmer, E.; Ungermann, J.; et al. Pollution trace gas distributions and their transport in the Asian monsoon upper troposphere and lowermost stratosphere during the StratoClim campaign 2017. Atmos. Chem. Phys. 2020, 20, 14695-14715. [CrossRef]

21. Woiwode, W.; Dörnbrack, A.; Bramberger, M.; Friedl-Vallon, F.; Haenel, F.; Höpfner, M.; Johansson, S.; Kretschmer, E.; Krisch, I.; Latzko, T.; et al. Mesoscale fine structure of a tropopause fold over mountains. Atmos. Chem. Phys. 2018, 18, 15643-15667. [CrossRef] 
22. Johansson, S.; Woiwode, W.; Höpfner, M.; Friedl-Vallon, F.; Kleinert, A.; Kretschmer, E.; Latzko, T.; Orphal, J.; Preusse, P.; Ungermann, J.; et al. Airborne limb-imaging measurements of temperature, $\mathrm{HNO}_{3}, \mathrm{O}_{3}, \mathrm{ClONO}_{2}, \mathrm{H}_{2} \mathrm{O}$ and $\mathrm{CFC}-12$ during the Arctic winter 2015/2016: Characterization, in situ validation and comparison to Aura/MLS. Atmos. Meas. Tech. 2018, 11, 4737-4756. [CrossRef]

23. Wetzel, G.; Friedl-Vallon, F.; Glatthor, N.; Grooß, J.U.; Gulde, T.; Höpfner, M.; Johansson, S.; Khosrawi, F.; Kirner, O.; Kleinert, A.; et al. Pollution trace gases $\mathrm{C}_{2} \mathrm{H}_{6}, \mathrm{C}_{2} \mathrm{H}_{2}, \mathrm{HCOOH}$, and PAN in the North Atlantic UTLS: Observations and simulations. Atmos. Chem. Phys. 2021, 21, 8213-8232. [CrossRef]

24. Piesch, C.; Sartorius, C.; Friedl-Vallon, F.; Gulde, T.; Heger, S.; Kretschmer, E.; Maucher, G.; Nordmeyer, H.; Barthel, J.; Ebersoldt, A.; et al. The mechanical and thermal setup of the GLORIA spectrometer. Atmos. Meas. Tech. 2015, 8, 1773-1787. [CrossRef]

25. Kleinert, A.; Friedl-Vallon, F.; Guggenmoser, T.; Höpfner, M.; Neubert, T.; Ribalda, R.; Sha, M.K.; Ungermann, J.; Blank, J.; Ebersoldt, A.; et al. Level 0 to 1 processing of the imaging Fourier transform spectrometer GLORIA: Generation of radiometrically and spectrally calibrated spectra. Atmos. Meas. Tech. 2014, 7, 4167-4184. [CrossRef]

26. Ungermann, J.; Kleinert, A.; Maucher, G.; Bartolomé, I.; Krasauskas, L.; Neubert, T.; Friedl-Vallon, F.; Johansson, S. On Quantifying and Mitigation GLORIA Instrument Effects and Uncertainties. 2021. In Preparation.

27. Höpfner, M.; Oelhaf, H.; Wetzel, G.; Friedl-Vallon, F.; Kleinert, A.; Lengel, A.; Maucher, G.; Nordmeyer, H.; Glatthor, N.; Stiller, G.; et al. Evidence of scattering of tropospheric radiation by PSCs in mid-IR limb emission spectra: MIPAS-B observations and KOPRA simulations. Geophys. Res. Lett. 2002, 29, 119-1-119-4. [CrossRef]

28. Stiller, G.P.; von Clarmann, T.; Funke, B.; Glatthor, N.; Hase, F.; Höpfner, M.; Linden, A. Sensitivity of trace gas abundances retrievals from infrared limb emission spectra to simplifying approximations in radiative transfer modelling. J. Quant. Spectrosc. Radiat. Transf. 2002, 72, 249-280. [CrossRef]

29. Rodgers, C.D. Inverse Methods for Atmospheric Sounding: Theory and Practice; World Scientific: Singapore, 2000 ; Volume 2.

30. Tikhonov, A.N. On the solution of ill-posed problems and the method of regularization. Dokl. Akad. Nauk SSSR 1963, 151, 501-504.

31. Hersbach, H.; Bell, B.; Berrisford, P.; Hirahara, S.; Horányi, A.; Muñoz-Sabater, J.; Nicolas, J.; Peubey, C.; Radu, R.; Schepers, D.; et al. The ERA5 global reanalysis. Q. J. R. Meteorol. Soc. 2020, 146, 1999-2049. [CrossRef]

32. Schneider, M.; Hase, F. Optimal estimation of tropospheric $\mathrm{H}_{2} \mathrm{O}$ and $\delta \mathrm{D}$ with IASI/METOP. Atmos. Chem. Phys. 2011, 11, 11207-11220. [CrossRef]

33. Borger, C.; Schneider, M.; Ertl, B.; Hase, F.; García, O.E.; Sommer, M.; Höpfner, M.; Tjemkes, S.A.; Calbet, X. Evaluation of MUSICA IASI tropospheric water vapour profiles using theoretical error assessments and comparisons to GRUAN Vaisala RS92 measurements. Atmos. Meas. Tech. 2018, 11, 4981-5006. [CrossRef]

34. Masuda, K.; Takashima, T.; Takayama, Y. Emissivity of pure and sea waters for the model sea surface in the infrared window regions. Remote Sens. Environ. 1988, 24, 313-329. [CrossRef]

35. Kleinert, A.; Krisch, I.; Ungermann, J.; Adibekyan, A.; Gutschwager, B.; Monte, C. Characterization of blackbody inhomogeneity and its effect on the retrieval results of the GLORIA instrument. Atmos. Meas. Tech. 2018, 11, 3871-3882. [CrossRef]

36. Clarmann, T.v.; Höpfner, M.; Kellmann, S.; Linden, A.; Chauhan, S.; Funke, B.; Grabowski, U.; Glatthor, N.; Kiefer, M.; Schieferdecker, T; et al. Retrieval of temperature, $\mathrm{H}_{2} \mathrm{O}, \mathrm{O}_{3}, \mathrm{HNO}_{3}, \mathrm{CH}_{4}, \mathrm{~N}_{2} \mathrm{O}, \mathrm{ClONO}_{2}$ and $\mathrm{ClO}$ from MIPAS reduced resolution nominal mode limb emission measurements. Atmos. Meas. Tech. 2009, 2, 159-175. [CrossRef]

37. EUMETSAT. IASI Level 2: Product Guide. Technical Report, EUM/OPS-EPS/MAN/04/0033. 2017. Available online: https:/ / www.eumetsat.int/media/45982 (accessed on 13 September 2021).

38. Wetzel, G.; Fischer, H.; Oelhaf, H. Remote sensing of trace gases in the midinfrared spectral region from a nadir view. Appl. Opt. 1995, 34, 467-479. [CrossRef] [PubMed] 